\title{
Shear bond strength of ceramic and metallic orthodontic brackets bonded with self-etching primer and conventional bonding adhesives
}

\author{
Valiollah Arash ${ }^{1}$, Fatemeh Naghipour ${ }^{2}$, Mehdi Ravadgar ${ }^{3}$, Ahmad Karkhah $^{4}$, Mohammad Saleh Barati ${ }^{5}$
}

${ }^{1}$ Orthodontist, Assistant Professor, Dental Material Research Center, Dental Faculty, Babol University of Medical Sciences, Babol, Iran

${ }^{2}$ General Dentist, Faculty Member, Dental Material Research Center, Dental Faculty, Babol University of Medical Sciences, Babol, Iran

${ }^{3}$ Orthodontist, Faculty Member, Department of Operative Dentistry, Dental Research Center, Shahid Beheshti University of Medical Sciences, Tehran, Iran

${ }^{4}$ General Practitioner, Faculty Member, Cellular and Molecular Biology Research Center, Faculty of Medicine, Babol University of Medical Sciences, Babol, Iran

${ }^{5}$ Orthodontist, Faculty Member, Dental Material Research Center, Dental Faculty, Babol University of Medical Sciences, Babol, Iran

\section{Type of article: Original}

\begin{abstract}
Introduction: Adult patients typically require high-quality orthodontic treatment for ceramic brackets, but some clinicians remain concerned about the bond strength of these brackets. Therefore, the aim of this study was to determine the shear bond strength and de-bonding characteristics of metallic and ceramic brackets bonded with two types of bonding agents.

Methods: In an experimental study done in 2013 in Babol, Iran, 120 extracted human maxillary premolar teeth were randomly divided into four groups as follows: HM group: metallic bracket/conventional bonding agent; SM group: metallic bracket/Transbond self-etching primer; HC group: ceramic bracket/conventional bonding agent; SC group: ceramic bracket/Transbond self-etching primer. Twenty-four hours after thermocycling (1000 cycle, 5 ${ }^{\circ} \mathrm{C}-55^{\circ} \mathrm{C}$ ), the shear bond strength values were measured. The amount of resin remaining on the tooth surface (adhesive remnant index: ARI) was determined under a stereomicroscope. Enamel detachment index was evaluated under a scanning electron microscope. To perform statistical analysis, ANOVA, Kruskal-Wallis, and Tukey post-hoc tests were applied. The level of significance was set at $\mathrm{p}<0.05$.

Results: The mean shear bond strength values $(\mathrm{MPa} \pm \mathrm{SD}$ ) were group $\mathrm{HM}=12.59$, group $\mathrm{SM}=11.15$, group $\mathrm{HC}=7.7$, and group $\mathrm{SC}=7.41$. Bond strength differences between groups $\mathrm{HM}$ and $\mathrm{SM}(\mathrm{p}=0.063)$ and between $\mathrm{HC}$ and $\mathrm{SC}(\mathrm{p}=0.091)$ were not statistically significant. There were significant differences between HM and HC and between SM and SC groups $(\mathrm{p}<0.05)$. Insignificant differences were found in ARI among all groups.

Conclusion: Our findings indicated that the metallic brackets had higher bond strengths in comparison with ceramic brackets. In addition, self-etching primer was able to produce fewer bonds compared with the conventional technique. Many samples showed the bracket-adhesive interface failure or failure inside the adhesive.
\end{abstract}

Keywords: Self-etching primer, Acid etching, Shear bond

\section{Introduction}

Phosphoric acid is the most widely used enamel surface conditioner $(1,2)$. Nowadays, phosphoric acid etching is known as a common and reliable method for bonding in orthodontics. Several studies have stated that clinical procedure simplification, significant decrease in chair time, and enamel loss along with maintaining the clinically

\section{Corresponding author:}

Dr. Mohammad Saleh Barati, Dental Material Research Center, Dental Faculty, Babol University of Medical Sciences, Babol, Iran. Tel: +98.9360803998, Email: Ahmadkarkhah@ymail.com

Received: June 11, 2016, Accepted: July 21, 2016, Published: January 2017

iThenticate screening: July 21, 2016, English editing: December 17, 2016, Quality control: January 05, 2017

(C) 2017 The Authors. This is an open access article under the terms of the Creative Commons Attribution-NonCommercialNoDerivs License, which permits use and distribution in any medium, provided the original work is properly cited, the use is non-commercial and no modifications or adaptations are made. 
acceptable bond strength are essential factors (2-6). To solve these problems, the combination of conditioning and priming agents into one acidic solution as self-etching primers (SEPs) have shown some advantages, including reduced enamel loss, prevention of saliva contamination, and less chair time. With the application of SEP, rinsing stage is also eliminated (7-11). Enamel acid-etching removes about 10 to $20 \mu \mathrm{m}$ of the enamel surface, but SEP has lower etching ability compared with acid-etch and provides a higher $\mathrm{pH}$ level on tooth surface, which consequently reduces potential damages to the enamel (12-14). These conditioners result in shorter resin tags based on scanning electron microscope (SEM) reports (15). Lower bond strength of SEP in comparison with the conventional method can be advantageous in reducing enamel fractures during bracket removal, especially the ceramic brackets, as they do not bend during de-bonding procedure $(9,16-18)$. However, bond strength of orthodontic brackets should be sufficient to withstand intraoral forces applied during the treatment period. According to Reynolds' investigation, the minimum acceptable shear bond strength in orthodontic clinic ranges from 5.9 to $7.8 \mathrm{MPa}$ (19). In the late 2000, the 3M Company introduced a new self-etching primer called Transbond Plus Self-Etching Primer (TPSEP) (14). Based on the aforementioned evidence, the purpose of this study was to compare the shear bond strength (SBS) of metallic and ceramic brackets bonded with TPSEP and conventional etching. Deboning characteristics were analyzed by adhesive remnant index (ARI) scoring and also scanning electron microscopic (SEM) evaluation.

\section{Material and Methods}

\subsection{The teeth, brackets, and bonding procedure}

A total of 120 human maxillary premolars without any caries, restorations, and cracks on the buccal enamel surface were collected. Sample size was determined to have adequate power of $(80 \%)$ and statistical significance at $\mathrm{p}<0.05$. The teeth were kept in chloramines $0.5 \%$ solution for one week and then in distilled water until the experiments were initiated. The teeth were cleaned and pumiced by using a rubber cup with fluoride-free paste for 10 seconds, thoroughly washed with water, and air-dried. The samples were randomly divided into four equal groups $(\mathrm{n}=30$ for each group), and the brackets were bonded to buccal surfaces according to the following principles:

2.1.1. Group 1 (HM): $37 \%$ phosphoric acid gel (Sina Co, Iran) was placed on the enamel surface for 15 seconds, washed with water spray for 30 seconds, and dried to a chalky white appearance. The primer solution, Transbond XT (3M Unitek, Monrovia, Calif), was then applied on the etched surface, and then it was light-cured for 5 seconds. Transbond XT composite resin (3M Unitek, South Peck Road, Monrovia, California, USA) was placed on upper premolar metal brackets (Standard-022, Dentaurum, Germany); the bracket was bonded to the tooth surface perpendicular to the long axis of the buccal surface with approximately $250 \mathrm{~g}$ force using a manual force gauge (Tension and Compression Gauge, Dentaurum, Germany). In all groups, the brackets were light-cured by LED lightcuring unit (Valo, Ultradent, USA) at a light intensity of $1000 \mathrm{~mW} / \mathrm{cm} 2$ for a total of 20 seconds, with the light beam directed for 10 seconds at each of the mesial and distal faces.

2.1.2. Group 2 (SM): Transbond plus self-etching primer (TPSEP)(3MUnitek) was gently rubbed onto the enamel surface for about 5 seconds according to manufacturer instruction, and the tooth surface was gently dried by a moisture-free air blower. Then metal brackets (Standard-022, Dentaurum, Germany) were bonded to the teeth with Transbond XT composite resin as in group 1.

2.1.3. Group $3(H C)$ : This group was prepared according to the method applied for Group 1, but using the upper premolar ceramic brackets (Standard-022, Dentaurum, Germany). Ceramic brackets were cured 20 seconds through the brackets.

2.1.4. Group $4(S C)$ : This group was prepared similar to Group 2, using upper premolar ceramic brackets (Standard022, Dentaurum, Germany). Ceramic brackets were cured 20 seconds through the brackets.

After water storage at $37^{\circ} \mathrm{C}$ for 24 hours, the samples were thermocycled for 1000 cycles between $5 \pm 2{ }^{\circ} \mathrm{C}$ and 55 $\pm 2^{\circ} \mathrm{C}$ using a digital thermocycling machine (Nemo Industrial Group, Mashhad, Iran) according to TR 11450 standards (30 seconds of warm water bath, 20 seconds of interval, and 30 seconds of cold water bath) (12).

\subsection{The de-bonding procedure}

Cylindrical-shaped molds of plaster, $1.5 \mathrm{~cm} \times 1.5 \mathrm{~cm}$, were prepared, which were filled with diluted self-curing acrylic resin (Acropars Co, Iran). Specimens were positioned in acrylic resin, in a way that the brackets were perpendicular to the shear blade. To evaluate the shear bond strength, the specimens were placed in a jig attached to the base plate of a machine (Zwick/Roell, Z 005, Germany), and the force was applied to the bracket-tooth interface with a blade at a crosshead speed of $0.5 \mathrm{~mm} /$ minute until the bracket was detached. The maximum force applied for de-bonding the bracket from tooth surface was recorded in Newton, and the shear bond strength was determined by dividing the force by bracket surface area $(9.93 \mathrm{~mm} 2$ and $6.79 \mathrm{~mm} 2$ as the surface area of metallic and ceramic brackets, respectively) (9). 


\subsection{Assessment of adhesive remnant (AR)}

Once the brackets had been de-bonded, the enamel surface of each tooth was under stereomicroscope (Olympus, SZx 9) with a magnification of 10x to determine the amount of residual adhesive on each tooth. The following scale was used to record ARI (adhesive remnant index) scores: 0, 1, 2, and 3 shows that no adhesive left on the tooth surface, less than half of the adhesive left on the tooth surface, more than half of the adhesive are on the tooth, all adhesive left on the tooth, respectively, with a distinct impression of the bracket mesh (20).

\subsection{Assessment of the enamel detachment}

For further investigation, the surface of all the brackets also was examined under a scanning electron microscope (SEM) (Philips, Netherlands, Model XL30), and an analysis system was installed on the device for qualitative measurement of enamel detachment and failure location. EDX analysis determined enamel detachment and site of bonding failure following de-bonding to a depth of $1.5 \mu \mathrm{m}$ in the bracket surface through measuring iron for metallic brackets, aluminum for ceramic brackets, silicon for adhesive resin, and phosphorus and calcium for the enamel (20). The enamel detachment index (EDI) was used to quantify detached enamel existing on the bracket bases after de-bonding: it consists of no enamel detachment(zero); less than 10\% of enamel detachment (one); more than $10 \%$ but less than $30 \%$ of enamel detachment(two). The average depth of X-ray infiltration was $1.5 \mathrm{~m}$.

\subsection{Statistical analysis}

The descriptive statistics, including the means and standard deviations, were calculated for SBS values. Statistical analysis was performed using the SPSS statistic 16.0 software (SPSS Inc. Chicago, Illinois, USA). One-way analysis of variance (ANOVA) was applied to determine any significant differences for SBS values among groups. The level of significance was predetermined at the $95 \%$ confidence level $(p<0.05)$.

\section{Results}

\subsection{The shear bond strength}

The mean shearing bond strengths and standard deviation in groups $\mathrm{HM}, \mathrm{SM}, \mathrm{HC}$, and $\mathrm{SC}$ were $12.59 \pm 2.61 \mathrm{MPa}$, $11.15 \pm 3.48 \mathrm{MPa}, 7.70 \pm 1.71 \mathrm{MPa}$, and $7.41 \pm 2.09 \mathrm{MPa}$, respectively. There was a significant difference in the mean shearing bond strengths between the four experimental groups $(p<0.0005, f=3,9)$ according to obtained results from one-way ANOVA analysis (Table 1). A post-hoc Tukey test did not confirm any statistically significant difference on the mean shearing bond strengths between groups HM and SM $(p=0.063)$ as well as between groups $\mathrm{HC}$ and SC $(\mathrm{p}=0.91)$. However, significant differences between HM and HC $(\mathrm{p}=0.04)$, and also between SM and $\mathrm{SC}$ groups $(\mathrm{p}=0.035)$ was observed.

\subsection{ARI scoring}

The ARI scores for adhesive remaining after de-bonding are shown in Table 2. Non-parametric analysis of KruskalWallis showed no significant differences between groups $(\mathrm{p}=0.65)$. Score 0 in 5 samples, score 1 in 43 samples, score 2 in 46 samples, and score 3 in 24 samples were observed. Enamel fractures (EFs) were found in group HM.

\subsection{Enamel detachment and failure location}

As shown in Table 3, SEM examination showed that no enamel detachment was found in 39 specimens and that most of them were located in the HC group. In addition, less than $10 \%$ of enamel detachment was found in 39 specimens; most of them were located in HM group. Moreover, greater than $10 \%$ of enamel detachment were found in two specimens located in HM and SM groups.

\subsection{Location of bonding failure}

De-bonding was observed in all groups mostly inside the adhesive itself and bracket-adhesive interface. Furthermore, as shown in Table 4 a part of the adhesive remained on the bracket and another part remained on the tooth surface during de-bonding procedure. There was no case of bracket failure.

Table 1. Comparison of shearing bond strengths in the experimental groups.

\begin{tabular}{|c|c|c|c|}
\hline Study groups & $n$ & Mean & SD \\
\hline $\mathrm{HM}^{*}$ & 30 & 12.59 & 2.61 \\
\hline $\mathrm{SM}^{* *}$ & 30 & 11.15 & 3.48 \\
\hline $\mathrm{HC}^{* * *}$ & 30 & 7.70 & 1.71 \\
\hline $\mathrm{SC}^{* * * *}$ & 30 & 7.41 & 2.09 \\
\hline
\end{tabular}

*HM: Hydrophosphoric acid and metal bracket; **SM: Self-etch primer and metal bracket; ***HC: Hydrophosphoric acid and ceramic bracket; ****SC: Self-etch primer and ceramic bracket 
Table 2. Comparison of ARI between the groups.

\begin{tabular}{|l|l|l|l|l|l|l|}
\hline \multirow{2}{*}{ Group } & \multicolumn{4}{|l|}{ Scores* } & \multirow{2}{*}{ EF (\%) } & \multirow{n}{*}{ n } \\
\cline { 2 - 7 } & 0 & 1 & 2 & 3 & & \\
\hline HM & 0 & 9 & 13 & 6 & 2 & 30 \\
\hline SM & 2 & 13 & 10 & 5 & 0 & 30 \\
\hline HC & 0 & 10 & 11 & 9 & 0 & 30 \\
\hline SC & 3 & 11 & 12 & 4 & 0 & 30 \\
\hline
\end{tabular}

*Score 0: no adhesive on the tooth; *Score 1: less than half of the adhesive left on the tooth; *Score 2: more than half of the adhesive left on the tooth; *Score 3: all adhesive left on the tooth, with a distinct impression of the bracket mesh.

Table 3. Comparison of EDI between the groups.

\begin{tabular}{|l|l|l|l|}
\hline \multirow{2}{*}{ Group } & \multicolumn{3}{|l|}{ EDI* } \\
\cline { 2 - 4 } & 0 & 1 & 2 \\
\hline HM & 6 & 13 & 1 \\
\hline SM & 11 & 8 & 1 \\
\hline HC & 12 & 8 & 0 \\
\hline SC & 10 & 10 & 0 \\
\hline
\end{tabular}

$* 0$ : no enamel detachment; * 1 : less than $10 \%$ of enamel detachment; *2: less than $30 \%$, greater than $10 \%$ of enamel detachment.

Table 4. Comparison of the type of de-bonding in the experimental groups.

\begin{tabular}{|l|l|l|l|}
\hline \multirow{2}{*}{ Groups } & \multicolumn{3}{|l|}{ Bond failure } \\
\cline { 2 - 4 } & En-Ad & Ad & Br-Ad \\
\hline HM & 0 & 22 & 6 \\
\hline SM & 2 & 23 & 5 \\
\hline HC & 0 & 21 & 9 \\
\hline SC & 3 & 23 & 4 \\
\hline
\end{tabular}

En-Ad: Enamel-adhesive interface; Ad: Intra-adhesive; Br-Ad: Bracket-adhesive interface

\section{Discussion}

Adult patients seek for premium orthodontic with ceramic brackets, but here we are still concerned about their bond strength. Therefore, traditional techniques because of lacking tooth-conserving and time-saving advantages are substituting with new procedures. Nowadays, the use of $37 \%$ phosphoric acid and Transbond XT might be known as the most common protocol for orthodontists in their experimental studies (22). Because of production of a gentler etch pattern, SEP is known as a popular choice, and it is used for enamel conditioning among orthodontists. The current study was conducted to determine the shearing bond strength of metallic and ceramic brackets with conventional bonding technique versus self-etching primer technique. Obtained results demonstrated that mean shearing bond strengths of A, B, C, and D groups were 12.59, 11.15, 9.70, and 8.40 MPa, respectively. As suggested by other authors, the values in all the cases were higher than the minimum values and lower than maximum values (23). Our results showed that bonding of metallic and ceramic brackets with the conventional and self-etching primer techniques did not show a statistically significant difference in mean shearing bond strength $(\mathrm{p}=0.071$ for metallic brackets and $p=0.35$ for ceramic brackets). Similar to our study, several investigations have reported that, by means of conventional method, the shearing bond strength is higher in comparison with using a self-etching primer method. However, there were no statistically significant differences between the shearing bond strength of conventional method and self-etching primer technique (24-27). Furthermore, several lines of evidence demonstrated that, by using conventional methods, the produced bond strength is remarkably greater compared with using a self-etching primer technique (17, 18, and 28). In contrast, the Bishara and Buyukyilmaz studies have indicated that the bond strength of the conventional method is less than the self-etching primer method $(29,30)$. These observed differences in the aforementioned investigations can be due to type of samples, study design, surface preparation, adhesives types, de-bonding techniques, time lapse, and teeth maintenance conditions. In a study, Uysal et al. indicated that bonding of ceramic brackets with $37 \%$ phosphoric acid produced a significantly higher shear bond strength in comparison with that of other groups. Also, the authors observed no significant difference between the other groups (3). Different working procedures and lack of thermocycling in the Uysal study may be the reason behind such a difference. Similar to the present research, the shear bond strength was higher in acid-etch than self- 
etch. Moreover, Mirzakouchaki et al. indicated no significant difference in the bond strength of metallic brackets prepared with the two methods nonetheless, it was significantly higher in metallic brackets compared with the ceramic ones (31). De-bonding was performed a week later, and the number of cycles during thermocycling was more in that study compared with the present research. In a study by Cacciafesta and Iijima, evaluating the conventional acid-etch and Transbond Plus self-etch primer in dry and contaminated environments, no significant difference was observed in the shear bond strength of metallic brackets between the two groups in a dry environment, which was consistent with the present study $(32,33)$. However, in a similar investigation by Zeppieri et al., the SBS of acid-etching method was reported to be considerably higher than that of Transbond Plus self-etching primer under dry conditions (34). In a study by Grubisa et al., comparing the shear bond strength between the three groups of A: TP self-etching primer plus Transbond XT composite resin, B: 35\% phosphoric acid plus Transbond XT composite resin, and C: 37\% phosphoric acid plus Enlight bonding composite resin, no significant difference was found between groups A and C; nevertheless, the shear bond strength of group B was significantly higher than that of the other groups (14). In another investigation by Basaran et al., the shear bond strength of $38 \%$ phosphoric acid was reported to be notably higher than that of Transbond Plus self-etch primer (11). Thermocycling was not performed and working approach was different from the present research.

The SBS of 37\% phosphoric acid and TP was compared by Elekdag et al. under different thermal cycles, and it was not different between two methods in the absence and/or after 5000 cycles of thermocycling; however, it was remarkably higher for acid etching following 2000 cycles of thermocycling. It can be perhaps argued that a greater number of thermocycling cycles reduces the amount of SBS through water penetration, weakening of the polymeric network compounds, and hydrolysis of the interfacial components; this condition places a greater impact on TP, possibly due to more conservative and less deep etching pattern in the (10). Both bovine incisors and procedures used in the aforementioned study differ from the present study. Comparing the metallic brackets with ceramic brackets, the former provides significantly a greater shear bond strength. These finding consist with the results of a study compared the metallic brackets (13.2 MPa) and ceramic brackets (8.8 MPa) with mechanical retention (25). In our study, although different bonding agents were used, bond strengths were similar in two bracket types. The results are not in accordance with the results of other investigations comparing metallic brackets and ceramic brackets with mechanical retention $(29,35)$. These differences in the results could be due to differences in device use, adhesives and bonding agents, force application methods, the duration of force, the type of the brackets, and the thermocycling procedure. In the present study, score 1 and score 2 were considered. There was no significant difference for ARI between groups. There was no significant difference in ARI scores between conventional etching and TP self-etching primer in several studies that is consistent with our findings $(25-27,36)$. It was stated that in the conventional technique, adhesive on tooth surface is more than that in the self-etching primer. In a similar way, another study was suggested that, compared with ARI and the self-etching primer technique, there is an ARI higher in the conventional technique (27). Composite resin remaining on dental enamel after de-bonding necessitates cleaning the surface, which may be accompanied by superficial removal of the enamel. On the other hand, very high bond strength can cause enamel cracks or fractures during de-bonding; therefore, cleaning the residual resin from the tooth surface is probably less risky than the damages the de-bonding procedure can lead to. What is desirable in orthodontics is separating the brackets from the tooth without damaging the enamel at the end of the treatment. EFs have been found when the adhesion force exceeds $14 \mathrm{MPa}$ (37-39). The frequency of EFs goes up with increased bond strength. Our findings agree with those reports, since two EFs were observed in group HM. Nonetheless, in vitro de-bonding increases the frequency of EFs, and orthodontists can avoid this side effect with gentler clinical debonding $(15,40)$. In addition, in vivo bond strength has been shown to be significantly lower than the in vitro one, suggesting that the frequency of EFs might be lower under clinical conditions (41). According to EDI analysis, enamel detachment was deep only in 3 samples (score 2). Detachment after de-bonding in other samples was zero or less than $10 \%$. There was no statistically significant difference among study groups. Evaluating the two types of metallic brackets bonded with No-Mix bonding systems, Sorel et al. found no significant difference in enamel detachment rate between the two brackets, and less than $10 \%$ of detachment was reported only in a small part of the bracket surface in both groups (8). Enamel detachment rate in the current study was lower than that in Sorel et al.'s research. The differences observed might be attributed to different methods of sample preparation in the two studies. However, there was consistency between the data obtained by EDI and the ARI scoring scale in both, as we did not see statistically significant difference between study groups, too. Enamel detachment by score 2 in the HM group can be related to enamel fracture registered by ARI because of more shear bond strength in this group.

In terms of comparison between ARI and EDX, the most important point is that EDX analysis is microscopic, while the ARI scale is macroscopic; the failure process is complicated and at different levels and regarding the different 
influential factors such as thickness of the adhesive materials, which is not considered in ARI but is of high importance in the microscopic view; thus, the two analyses cannot be compared among all the groups and conditions. Although there was no statistically meaningful relationship between the type of bonding failure between different groups, most bonding failures were seen in the bracket-composite interface and in the adhesive itself $(\mathrm{p}=$ 0.66). Romano et al. reported findings similar to these results. (18). In addition, Perdigao et al. demonstrated more bonding failures in the self-etching primer technique in the adhesive. The authors suggested that this bonding failure might be due to the shallow etching in the technique (42). The result of another study demonstrated that most failures occurred in the dry environment, in the bracket-composite junction, or internal part of the adhesive interface. Besides, in the traditional method, the enamel-adhesive interface was shown the most fail section. Thus, bonding-related failure depends on saliva contamination or no-salvia contamination. Given the remaining composite resin on both surfaces of the teeth and the brackets in self-etching and acid-etching methods, Uysal et al. reported that the majority of failures occurred within the composite resin (3). Several factors such as type of bracket, contamination or lack of contamination with saliva, and composite type can be involved in determination of bonding failure location. Although this study took some advantages, there were several limitations, including sample size and lack of facilities in our research center. However, more studies are required to compare shear bond strength of ceramic and metallic orthodontic brackets. Comparing results for pediatric and adult patients with different bonding techniques also should be suggested for future studies.

\section{Conclusions}

Obtained results demonstrated that metallic brackets had significantly higher bond strengths compared with ceramic brackets. The self-etching primer method in comparison with the conventional method was able to create weaker bond strengths. However, this difference was not statistically significant, but it can be acceptable in clinics. According to ARI scores, it appears no concerns about enamel damage in the course of de-bonding with the two types of brackets and two bonding types used. Many samples indicated that bracket-adhesive interference failure or failure inside the adhesive itself could probably show a reduced chance of enamel damage.

\section{Acknowledgments:}

This study was financially supported by the Research and Technology Council of Babol University of Medical Sciences.

\section{Conflict of Interest:}

There is no conflict of interest to be declared.

Authors' contributions:

All authors contributed to this project and article equally. All authors read and approved the final manuscript.

\section{References:}

1) Buonocore MG. A simple method of increasing the adhesion of acrylic filling materials to enamel surfaces. J Dent Res. 1955; 34(6): 849-53. doi: 10.1177/00220345550340060801. PMID: 13271655.

2) Uysal T, Ulker M, Ramoglu SI, Ertas H. Microleakage under metallic and ceramic brackets bonded with orthodontic self-etching primer systems. Angle Orthod. 2008; 78(6): 1089-94. doi: 10.2319/100507-481.1. PMID: 18947278.

3) Uysal T, Ustdal A, Kurt G. Evaluation of shear bond strength of metallic and ceramic brackets bonded to enamel prepared with self-etching primer. Eur J Orthod. 2010; 32(2): 214-8. doi: 10.1093/ejo/cjp035. PMID: 19509345.

4) Bayne SC, Thompson JY. Biomaterials in Sturdevant S, Heymann HO, Edward J, Swift JR. Art \& science operative dentistry. 5th Edition. 2006; 182-6.

5) Montasser MA, Drummond JL. Relibility of the adhesive remnant index score system with different magnifications. Angle Orthod. 2009; 79(4): 773-6. doi: 10.2319/080108-398.1. PMID: 19537872.

6) Ireland AJ, Knight H, Sherriff M. An in vivo investigation into bond failure rates with a new self-etching system. Am J Orthod Dentofacial Orthop. 2003; 124(3): 323-6. doi: 10.1016/S0889-5406(03)00403-7. PMID: 12970667.

7) Dorminey JC, Dunn WJ, Taloumis LJ. Shear bond strength of orthodontics brackets bonded with a modified 1-stepetchant-and-primer technique. Am J Orthod Dentofacial Orthop. 2003; 124(4): 410-3. doi: 10.1016/S0889-5406(03)00404-9. 
8) Sorel O, El Alam R, Chagneau F, Cathelineau G. Comparison of bond strength between simple foil mesh and laser-structured base retention brackets. Am J Orthod Dentofacial Orthop. 2002; 122(3): 260-6. doi: 10.1067/mod.2002.125834. PMID: 12226606.

9) Yuasa T, Iijima M, Ito SH, Muguruma T, Saito T, Mizoguchi I. Effect of long-term storage and thermocycling on bond strength of two self-etching primer adhesive systems. Eur J Orthod. 2010; 32(3): 285-90. doi: 10.1093/ejo/cjp118. PMID: 19969525.

10) Elekdag-Turk S, Turk T, Isci D, Ozkalayci N. Thermocycling effects on shear bond strength of a selfetching primer. Angle Orthod. 2008; 78(2): 351-6. doi: 10.2319/122906-537.1. PMID: 18251621.

11) Başaran G, Ozer T, Devecioğlu Kama J. Comparison of a recently developed nanofiller self-etching primer adhesive with other self-etching primers and conventional acid etching. Eur J Orthod. 2009; 31(3): 271-5. doi: 10.1093/ejo/cjn103. PMID: 19233930.

12) Newman GV. Epoxy adhesive for orthodontic attachments: progress report. Am J Orthod. 1965; 51(12): 901-12. doi: 10.1016/0002-9416(65)90203-4. PMID: 5214895.

13) House K, Ireland AJ, Sherriff M. An investigation into the use of a single component self-etching primer adhesive system for orthodontic bonding: a randomized controlled clinical trial. J of Orthod. 2006; 33(1): 38-44. doi: 10.1179/146531205225021375. PMID: 16514132.

14) Grubisa HS, Heo G, Raboud D, Glover KE, Major PW. An evaluation and comparison of orthodontic bracket bond strengths achieved with self-etching primer. Am J Orthod and Dentofacial Orthop. 2004; 126(2): 213-9. doi: 10.1016/j.ajodo.2004.01.016. PMID: 15316477.

15) Vilchis RJ, Hotta Y, Yamamoto K. Examination of the enamel-adhesive interface with focused ion beam and scanning electron microscopy. Am J Orthod Dentofacial Orthop. 2007; 131(5): 646-50. doi: 10.1016/j.ajodo.2006.11.017. PMID: 17482085.

16) Bishara SE, Oonsombat C, Soliman MM, Warren JJ, Laffoon JF, Ajlouni R. Comparison of bonding time and shear strength between a conventional and a new integrated bonding system. Angle Orthod. 2005; 75(2): 237-42. PMID: 15825789.

17) Bishara SE, VonWald L, Laffoon JF, Warren JJ. Effect of a self-etching primer/adhesive on the shear bond strength of orthodontic brackets. Am J Orthod and Dentofacial Orthop. 2001; 119(6): 621-4. doi: 10.1067/mod.2001.113269. PMID: 11395706.

18) Romano FL, Tavares SW, Nouer DF, Consani S, Borges de Araújo Magnani MB. Shear bond strength of metallic orthodontic brackets bonded to enamel prepared with self-etching primer. Angle Orthod. 2005; 75(5): 849-53. doi: 10.1043/0003-3219(2005)75[849:SBSOMO]2.0.CO;2. PMID: 16285044.

19) Reynolds IR. A review of direct orthodontic bonding. Br J Orthod. 1975; 2(3): 171-8. doi: 10.1080/0301228X.1975.11743666.

20) Artun J, Bergland S. Clinical trials with crystal growth conditioningas an alternative to acid-etch enamel pretreatment. Am J Orthod. 1984; 85(4): 333-40. doi: 10.1016/0002-9416(84)90190-8. PMID: 6231863.

21) Hosein I, Sherriff M, Ireland AJ. Enamel loss during bonding, debonding, and cleanup with use of a selfetching primer. Am J Orthod Dentofacial Orthop. 2004; 126(6): 717-24. doi: 10.1016/j.ajodo.2003.10.032. PMID: 15592221.

22) Artun N, Arman A, Cehreli SB, Arikan S, Karabulut E, Gulsahi K. Microleakage beneath ceramic and metal brackets bonded with a conventional and an antibacterial adhesive system. Angle Orthod. 2006; 76(6): 1028-34. doi: 10.2319/101805-368.

23) Bishara SE, Olsen ME, Von Wald L. Evaluation of debonding characteristics of a new collapsi-ble ceramic bracket. Am J Orthod Dentofacial Orthop. 1997; 112(5): 552-9. doi: 10.1016/S0889-5406(97)70083-0.

24) Perdigão J, Lopes L, Lambrechts P, Leitão J, Van Meerbeek B, Vanherle G. Effects of a self-etching primer on enamel shear bond strengths and SEM morphology. Am J Dent. 1997; 10(3): 141-6. PMID: 9580237.

25) Korbmacher H, Klocke A, Huck L, Kahl-Nieke B. Enamel condi $\neg$ tioning for orthodontic bonding with a single-step bonding agent. J Orofac Orthop. 2002; 63(6): 463-71. doi: 10.1007/s00056-002-0130-5. PMID: 12444530 .

26) Velo S, Carano A, Carano A. Self-etching vs. traditional bonding systems in orthodontics: an in vitro study. Orthod Craniofac Res. 2002; 5(3): 166-9. doi: 10.1034/j.1600-0544.2002.02193.x. PMID: 12194666.

27) Cal-Neto JP, de Miranda MS, Dias KR. Comparative SEM evaluation of penetration of adhesive systems in human dentin with a non-rinse conditioner and a self-etching primer. Braz Dent J. 2004; 15(1): 19-25. doi: 10.1590/S0103-64402004000100004. PMID: 15322640.

28) Yamada R, Hayakawa T, Kasai K. Effect of using self-etching primer for bonding orthodontic brackets. Angle Orthod. 2002; 72(6): 558-64. doi: 10.1043/0003-3219(2002)072<0558:EOUSEP>2.0.CO;2. PMID: 12518948. 
29) Bishara SE, Soliman MM, Oonsombat C, Laffoon JF, Ajlouni R. The effect of variation mesh-base design on the shear bond strength of orthodontic brackets. Angle Orthod. 2004; 74(3): 400-5. doi: 10.1043/00033219(2004)074<0400:TEOVIM>2.0.CO;2. PMID: 15264654.

30) Buyukyilmaz T, Usumez S, Karaman AI. Effect of self-etching primers on bond strength--are they reliable?. Angle Orthod. 2003; 73(1): 64-70. doi: 10.1043/0003-3219(2003)073<0064:EOSEPO>2.0.CO;2. PMID: 12607857.

31) Mirzakouchaki, Kimyai S, Hydari M, Shahrbaf S, Mirzakouchaki-Boroujeni P. Effect of self-etching primer/adhesive and conventional bonding on the shear bond strength in metallic and ceramic brackets. Med Oral Patol Oral Cir Bucal. 2012; 17(1): e164-70. PMID: 21743430, PMCID: PMC3448178.

32) Cacciafesta V, Sfondrini MF, De Angelis M, Scribante A, Klersy C. Effect of water and saliva contamination on shear bond strength of brackets bonded with conventional, hydrophilic, and self-etching primers. Am J Orthod Dentofacial Orthop. 2003; 123(6): 633-40. doi: 10.1016/S0889540603001987. PMID: 12806342.

33) Iijima M, Ito S, Yuasa T, Muguruma T, Saito T, Mizoguchi I. Bond Strength Comparison and Scanning Electron Microscopic Evaluation of Three Orthodontic Bonding Systems. Dent Mater J. 2008; 27(3): 3929. doi: 10.4012/dmj.27.392. PMID: 18717167.

34) Zeppieri IL, Chung CH, Mante FK. Effect of saliva on shear bond strength of an orthodontic adhesive used with moisture-insensitive and self-etching primers. Am J Orthod Dentofacial Orthop. 2003; 124(4): 414-9. doi: 10.1016/S0889-5406(03)00405-0. PMID: 14560272.

35) Liu JK, Chung CH, Chang CY, Shieh DB. Bond strength and debonding characteristics of a new ceramic bracket. Am J Orthod Dentofacial Orthop. 2005; 128(6): 761-5. doi: 10.1016/j.ajodo.2004.03.041. PMID: 16360918.

36) Bishara SE, VonWald L, Laffoon JF, Warren JJ. Effect of a self-etch primer/adhesive on the shear bond strength of orthodontic brackets. Am J Orthod Dentofacial Orthop. 2001; 119(6): 621-4. doi: 10.1067/mod.2001.113269. PMID: 11395706.

37) Eminkahyagil N, Arman A, etinsahin A, Karabulut E. Effect of resin-removal methods on enamel and shear bond strength of rebonded brackets. Angle Orthod. 2006; 76(2): 314-21. doi: 10.1043/00033219(2006)076[0314:EORMOE]2.0.CO;2. PMID: 16539561.

38) Tecco S, Traini T, Caputi S, Festa F, de Luca V, D’Attilio M. A new one-step dental flowable composite for orthodontic use: an in vitro bond strength study. Angle Orthod. 2005; 75(4): 672-7. doi: 10.1043/00033219(2005)75[672:ANODFC]2.0.CO;2. PMID: 16097240.

39) Trites B, Foley TF, Banting D. Bond strength comparison of 2 self-etching primers over a 3-month storage period. Am J Orthod Dentofacial Orthop. 2004; 126(6): 709-16. doi: 10.1016/j.ajodo.2003.09.032. PMID: 15592220.

40) Rix D, Foley TF, Mamandras A. Comparison of bond strength of three adhesives: composite resin, hybrid GIC, and glass-filled GIC. Am J Orthod Dentofacial Orthop. 2001; 119(1): 36-42. doi: 10.1067/mod.2001.110519. PMID: 11174538.

41) Hajrassie MK, Khier SE. In-vivo and in-vitro comparison of bond strengths of orthodontic brackets bonded to enamel and debonded at various times. Am J Orthod Dentofacial Orthop. 2007; 131(3): 384-90. doi: 10.1016/j.ajodo.2005.06.025. PMID: 17346595.

42) Perdigão J, Lopes L, Lambrechts P, Leitão J, Van Meerbeek B, Vanherle G. Effects of a self-etching primer on enamel shear bond strengths and SEM morphology. Am J Dent. 1997; 10(3): 141-6. PMID: 9580237. 